\title{
RANCANG BANGUN E-GALLERY SLB WIYATA DARMA KOTA METRO BERBASIS WEB MENGGUNAKAN METODE SDLC
}

\author{
Yeni Ambar Wati 1), Dani Anggoro ${ }^{2)}$, Arif Hidayat ${ }^{3)}$ \\ 1-3*) Program Studi Ilmu Komputer, Fakultas IImu Komputer, \\ Universitas Muhammadiyah Metro
}

Alamat : Jl. Gatot Subroto No.100, Yosodadi, Metro Timur, Kota Metro - Lampung

\begin{abstract}
Abstrak : Dari hasil penelitian Galeri di SLB Wiyata Dharma Kota Metro merupakan sebuah ruangan yang digunakan untuk menyimpan barang sekaligus sarana pemasaran produkproduk yang telah selesai diproduksi dan siap untuk dijual. Adapun tujuan penelitian ini adalah untuk membuat sistem penjualan offline (manual) menjadi online (terkomputerisasi) agar memudahkan penjual dalam melakukan pemasaran, dan memudahkan pembeli dalam melakukan pembelian barang, dengan adanya permasalahan tersebut maka dibangun sebuah sistem "Rancang Bangun E-Gallery SLB Wiyata Dharma Kota Metro Berbasis Web Menggunakan Metode SDLC". Perancangan E-Gallery menggunakan metode SDLC (System Development Life Cycle), Framework yang digunakan adalah Codelgniter, menggunakan bahasa pemrograman PHP, dan MySQL sebagai databasenya, dan untuk pengujian perangkat lunak menggunakan metode BlackBox Testing.
\end{abstract}

Kata Kunci: Rancang Bangun, E-Gallery, PHP, SDLC, MySQL, BlackBox Testing, dan Codelgniter

Abstract: The gallery at SLB Wiyata Dharma Metro City is a room that is used to store goods as well as a means of marketing products that have been produced and are ready to be sold. The purpose of this research is to make an offline (manual) sales system online (computerized) in order to make it easier for every user such as a seller in doing marketing, and buyers in purchasing goods, with these problems, a system "Design E-Gallery SLB is built. Wiyata Dharma Kota Metro Web-Based Using the SDLC Method". The design of the EGallery uses the SDLC (System Development Life Cycle) method, the Framework used by Codelgniter, using the PHP programming language, and MySQL as the database, and for software testing using the BlackBox Testing method.

Keywords : Design, E-Gallery, PHP, SDLC, MySQL, BlackBox Testing, and Codelgniter

\section{PENDAHULUAN}

SLB Wiyata Dharma menyediakan bengkel pembuatan produk kreatifitas seperti batik ciprat, sandal santai, dan kriya kayu bertujuan untuk menjadi peluang bagi peserta didik untuk mengembangkan kemampuan. Produk-produk yang dihasilkan oleh bengkel keterampilan tersebut seperti batik ciprat, sandal santai dan kriya kayu akan dipajang dan disusun rapi dalam ruang khusus yang disebut dengan galeri silabi. Galeri silabi merupakan tempat yang disediakan oleh SLB Wiyata Dharma Kota Metro yang digunakan khusus untuk sarana pemasaran kepada para pembeli yang berkunjung ke SLB Wiyata Dharma Kota Metro.

Sistem penjualan produk kreativitas pada galeri silabi saat ini masih menggunakan sistem offline, yaitu dengan bertemu langsung dengan pembeli, proses pembayaran masih menggunakan uang 
tunai, bukti pembayaran menggunakan nota pembayaran. Selain itu, kelemahan pada galeri silabi saat ini adalah penyajian informasi belum terpublikasi secara luas karena belum menggunakan sistem secara online sehingga masih banyak masyarakat yang diluar kota metro belum mengenal produk tersebut.

Agar proses pemasaran dapat terpublikasi secara luas, maka penulis tertarik untuk melakukan sebuah penelitian dan pembuatan e-gallery berbasis web yang berjudul "Rancang Bangun E-Gallery SLB Wiyata Dharma Kota Metro Berbasis WEB Menggunakan Metode SDLC" dengan maksud dan tujuan mengembangkan dan mempromosikan produk unggulan berupa batik ciprat, sandal, dan kerajinan kayu agar dapat terpublikasi secara luas pada masyarakat baik di luar kota maupun di luar negeri.

Berdasarkan uraian pada latar belakang maka rumusan masalah yang muncul adalah sebagai berikut:

a. Bagaimana cara membangun EGallery SLB Wiyata Dharma Kota Metro berbasis WEB?

b. Bagaimana menggunakan metode SDLC dalam rancang bangun $E$ Gallery SLB Wiyata Dharma Kota Metro?

Tujuan dari penelitian ini diantaranya adalah:

a. Membangun E-Gallery SLB Wiyata Dharma Kota Metro berbasis Web

b. Menggunakan metode SDLC dalam rancang bangun E-Gallery SLB Wiyata Dharma Kota Metro

Data dan informasi yang digunakan dalam penelitian ini merupakan hasil riset yang telah dilakukan selama 15 hari yaitu pada tanggal 01 sampai dengan 15 Desember 2020 di SLB Wiyata Dharma Kota Metro tepatnya pada bagian galeri silabi tempat penjualan produk, tujuan dari penelitian ini adalah membangun sebuah website penjualan yang diusulkan mampu untuk berjualan secara online. Untuk mencapai tujuan penelitian maka penulis menggunakan bahasa pemrograman PHP dan framework Codelgniter, dan metode pengembangan perangkat lunak yang digunakan adalah model SDLC (Software Development Life Cycle), Metode ini terdapat beberapa tahapan diantaranya analisis, desain, implementasi, testing, dan evolusi.

\section{KAJIAN PUSTAKA DAN LANDASAN TEORI}

\section{Rancang dan Bangun}

Pressman (2010 :13), yang dikutip Made Agus Suartika (2019: 9) menyimpulkan rancang bangun adalah: "Rancang Bangun merupakan serangkaian prosedur untuk menerjemahkan hasil analisa dari sebuah sistem kedalam bahasa pemrograman untuk mendeskripsikan dengan detail bagaimana komponen-komponen sistem diimplementasikan.

\section{E-Gallery}

Maulina, et.al., (2019:234) menyimpulkan beberapa manfaat e-gallery sebagai berikut:

a. E-gallery dapat dijadikan media informasi

b. E-Gallery dapat dijadikan media pendukung promosi karya seni

\section{PHP}

Supono dan Putratama (2016 :3) berpendapat bahwa PHP (Hypertext Preprocessor) adalah:

"suatu bahasa pemrograman yang digunakan untuk menerjemahkan baris kode program menjadi kode mesin yang dapat dimengerti oleh komputer yang berbasis server-side yang dapat ditambahkan ke dalam HTML". Dari 
pengertian diatas penulis dapat menyimpulkan bahwa PHP (Hypertext Preprocessor) adalah bahasa script serverside dalam pengembangan web yang disisipkan pada dokumen HTML.

\section{MySQL}

Nugroho (2019) menyimpulkan bahwa: "MySQL adalah database yang paling digemari di kalangan programmer web, dengan alasan bahwa program ini merupakan database yang sangat kuat dan cukup stabil untuk digunakan sebagai media penyimpanan data".

Sulhan (2007:118) menyimpulkan bahwa: "MySQL merupakan perangkat lunak yang digunakan untuk membangun database yang sering digunakan di lingkungan linux. MySQL merupakan software open source yang berarti free untuk digunakan. Selain di lingkungan linux, MySQL juga tersedia di lingkungan windows".

\section{Black Box Testing}

Black Box testing adalah tahap yang digunakan untuk menguji kelancaran program yang telah dibuat. Pengujian ini penting dilakukan agar tidak terjadi kesalahan alur program yang telah dibuat. Rosa , et.al.,(2015 :275) menyimpulkan bahwa Blackbox Testing adalah "Blackbox testing yaitu menguji perangkat lunak dari segi spesifikasi fungsional tanpa menguji desain dan kode program".

Rizky (2011 :264) menyimpulkan bahwa Blackbox Testing adalah "Blackbox testing adalah tipe testing yang memperlakukan perangkat lunak yang tidak diketahui kinerja internalnya".

\section{Codelgniter}

Ibnu (2011:2), memberi kesimpulan bahwa Framework Codelgniter adalah:

"Sebuah framework telah berisi sekumpulan arsitektur/ konsep-konsep yang dapat mempermudah dalam pemecahan sebuah masalah. Framework sebuah konstruksi dasar yang menopang sebuah konsep atau sistem yang bersifat essential support (penting tapi bukan komponen utama)".

Ibnu (2011:3), memberi kesimpulan bahwa Framework Codelgniter adalah:

"Codeigniter adalah sebuah web application framework yang bersifat open source digunakan untuk membangun aplikasi php dinamis. Tujuan utama pengembangan Codeigniter adalah untuk membantu developer untuk mengerjakan aplikasi lebih cepat daripada menulis semua code dari pengembangan".

\section{METODE}

\section{Jenis Penelitian}

Penelitian yang dilakukan termasuk jenis kualitatif. Adapun yang dimaksud dengan penelitian kualitatif adalah penelitian yang tidak menggunakan model statistik, komputerisasi, atau matematik.

Menurut Moleong (2011: 6) menarik kesimpulan sebagai berikut:

"Penelitian kualitatif adalah penelitian yang bermaksud untuk memahami fenomena tentang apa yang dialami oleh subjek penelitian secara holistik"

\section{Metode Pengumpulan Data}

Merupakan teknik dimana peneliti turun ke lapangan penelitian

a. Observasi (Observation)

Observasi merupakan kegiatan yang dilakukan oleh peneliti dengan cara mengamati secara langsung ditempat penelitian. Data yang diperoleh peneliti pada saat observasi adalah mengetahui bagaimana proses pembuatan produk unggulan dan mengetahui proses penjualan produk yang sedang berlangsung.

\section{Wawancara (Interview)}

Teknik wawancara biasanya dilakukan oleh tentang topik tertentu, pada penelitian ini wawancara berlangsung dengan lbu Titin susanti, S.Pd selaku Urusan produksi batik di SLB Wiyata Dharma Metro sesuai 
dengan judul yang diambil penulis. Data informasi yang diperoleh pada saat wawancara adalah proses penjualan yang sedang berjalan, pendataan barang yang masih digunakan, dan proses pembuatan produk unggulan.

\section{Dokumentasi (Documentation)}

Dokumentasi merupakan teknik yang dilakukan dengan cara mengumpulkan data yang memanfaatkan dokumen sebagai sumber utama, data yang diperoleh seperti sejarah berdirinya SLB Wiyata Dharma Kota Metro, struktur organisasi dan visi misi, data harga barang, nota pembayaran, data pesanan/ pemesan dan laporan penjualan.

\section{Metode Pengembangan Sistem}

Dalam penyusunan penelitian ini, penulis menggunakan metode SDLC untuk merancang sebuah aplikasi, karena dalam sebuah perancangan dibutuhkan sebuah urutan atau teknik perancangan agar aplikasi yang dihasilkan dapat berjalan dengan baik. Berikut merupakan gambar metode SDLC:

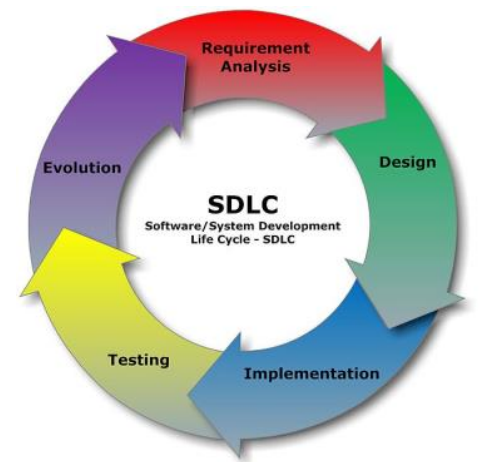

Gambar 1. SULC (Sumber: vVIKIwand)

\section{Tahap analisis}

Proses pengumpulan kebutuhan dilakukan secara intensif untuk menspesifikasikan kebutuhan perangkat lunak agar dapat dipahami perangkat lunak seperti apa yang dibutuhkan oleh user. Spesifikasi kebutuhan perangkat lunak pada tahap ini perlu untuk didokumentasikan

\section{a. Desain}

Desain perangkat lunak adalah proses multilangkah yang fokus pada desain pembuatan program perangkat lunak termasuk struktur data, arsitektur, perangkat lunak, representasi antarmuka, dan prosedur pengkodean. Tahap ini mentranslasi perangkat lunak dari tahap analisis kebutuhan ke representasi desain agar dapat diimplementasikan menjadi program pada tahap selanjutnya. Desain perangkat lunak yang dihasilkan pada tahap ini juga perlu didokumentasikan.

\section{b. Implementation}

Desain harus ditranslasikan ke dalam program perangkat lunak. Hasil dari tahap ini adalah program komputer sesuai dengan yang telah dibuat pada tahap desain.

\section{c. Testing (Pengujian)}

Pengujian foku pada perangkat lunak secara dari segi logik dan fungsional serta memastikan bahwa semua bagian sudah diuji. Hal ini dilakukan untuk meminimalisir kesalahan (error) dan memastikan keluaran yang dihasilkan sesuai dengan yang diinginkan.

\section{d. Evolution}

Tidak menutup kemungkinan sebuah perangkat lunak mengalami perubahan ketika sudah dikirim ke user. Perubahan biasanya terjadi karena adanya kesalahan yang muncul dan tidak terdeteksi saat pengujian atau perangkat lunak harus beradaptasi dengan lingkungan baru.

\section{HASIL DAN PEMBAHASAN}

Tujuan dari penelitian adalah membangun sebuah website e-gallery, sehingga peneliti mengambil judul "Rancang Bangun EGallery SLB Wiyata Dharma Kota Metro Berbasis Web Menggunakan Metode SDLC"Untuk itu diperlukan beberapa tahap penyelesaian diantaranya: 
a. Hasil Analisis

Data dan informasi yang digunakan dalam penelitian ini merupakan hasil riset yang telah dilakukan selama 15 hari yaitu pada tanggal 01 sampai dengan 15 Desember 2020 di SLB Wiyata Dharma Kota Metro tepatnya pada bagian galeri silabi tempat penjualan produk, tujuan dari penelitian ini adalah membangun sebuah website penjualan yang diusulkan mampu untuk berjualan secara online. Untuk mencapai tujuan penelitian maka penulis menggunakan bahasa pemrograman PHP dan framework Codelgniter, dan metode pengembangan perangkat lunak yang digunakan adalah model SDLC (Software Development Life Cycle), Metode ini terdapat beberapa tahapan diantaranya analisis kebutuhan, pembuatan kode program, pengujian.

b. Desain

1) Flowchart

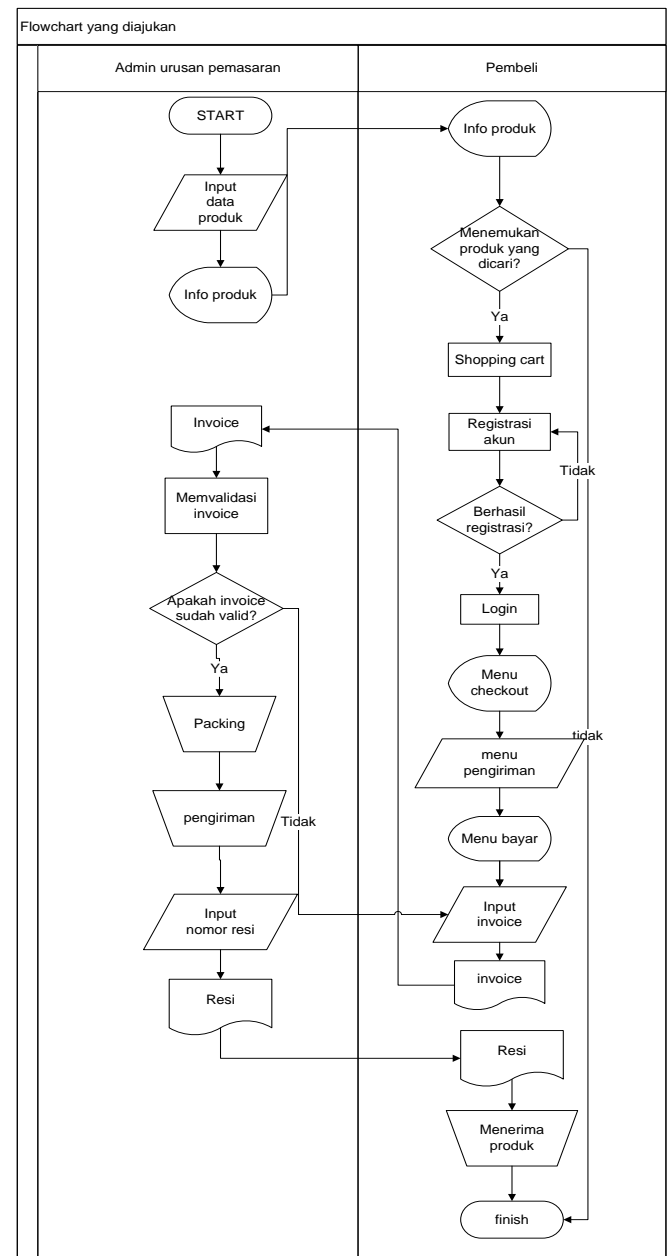

Gambar 2. Flowchart Yang Diajukan

2) Diagram Konteks level 0

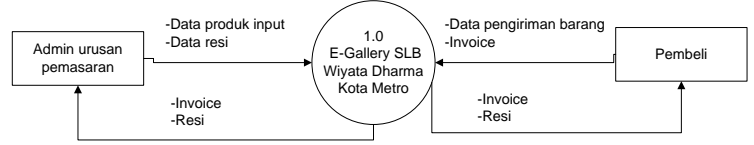

Gambar 3. Diagram Konteks level 0

3) ERD (Entity Relationship Diagram)

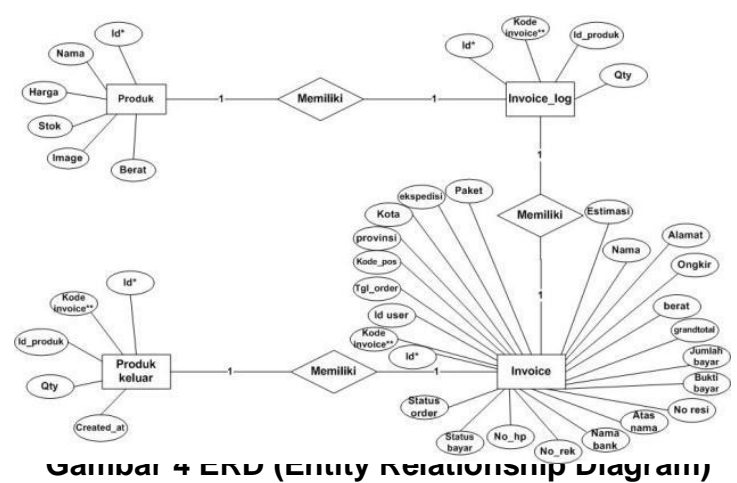


4) Relasi Tabel

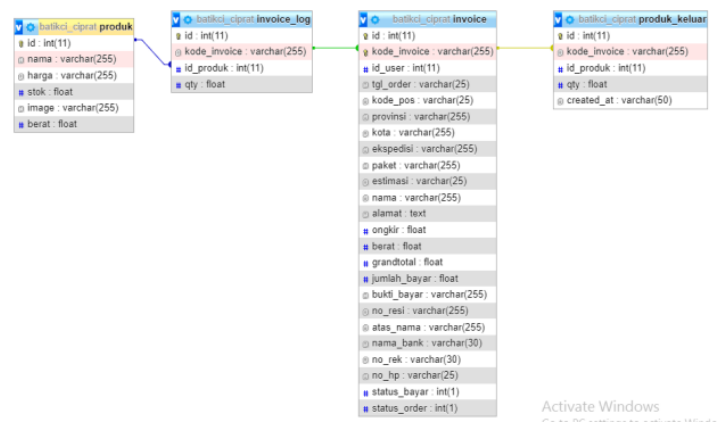

Gambar 5. Relasi Tabel

Berikut merupakan tampilan desain interface:

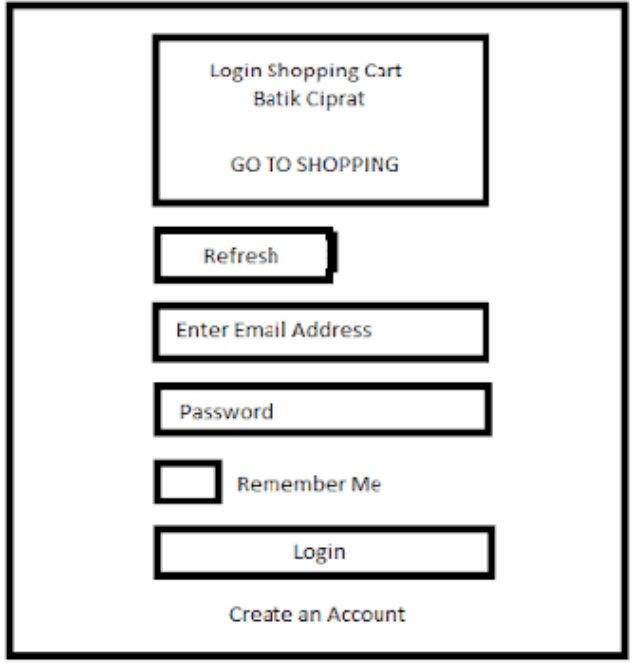

Gambar 6. Desain Tampilan Login

1. Enter email address digunakan untuk masukkan email

2. Password digunakan untuk memasukkan password

3. Create an account untuk registrasi akun

c. Implementation

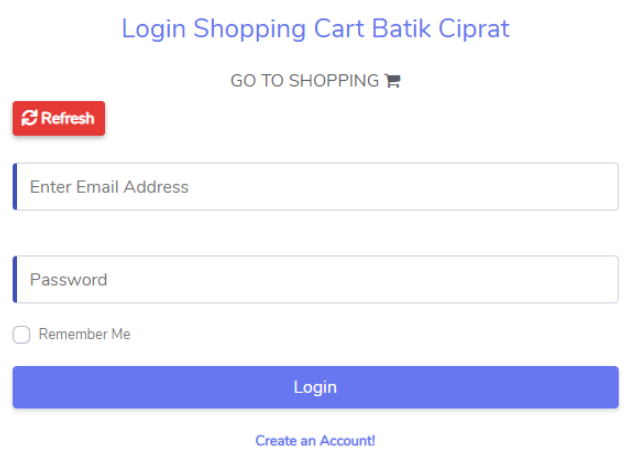

1. Enter email address digunakan untuk masukkan email

2. Password digunakan untuk memasukkan password

3. Create an account untuk registrasi akun

\section{KESIMPULAN}

Tujuan dibangunnya website ini adalah memudahkan pihak yang terkait. Pada pembangunan website ini Penulis menggunakan metode pengembangan SDLC (Software Development Life Cycle), Pengujian program menggunakan Black Box Testing. Penulis menarik kesimpulan bahwa tujuan dari penelitian ini sudah tercapai yang dimana telah menghasilkan sebuah website penjualan E-Gallery sesuai dengan tujuan dari riset penelitian yaitu Rancang Bangun E-Gallery SLB Wiyata Dharma Kota Metro Berbasis Web Menggunakan Metode SDLC.

\section{REFERENSI}

[1] Made Agus Suartika. 2019. Rancang Bangun E-Commerce Pada Galeri Umkm Kabupaten Sumbawa Berbasis Web. Sumbawa. Program Studi Informatika Fakultas Teknik Universitas Teknologi Sumbawa

[2] Linda Durrotul Ummah. 2018. Rancang Bangun E-Commerce Pada Toko Kerudung Nuri Collection Berbasis Customer Relationship Management. Jurnal Nuansa Informatika, 12(2), H.10-14

[3] Hadis riwayat Abu Dawud dari Syaikh Albani dalam Shahih Wa Dhaif Sunan Abu Dawud No.3641

[4] Ainun Dtf.2017. Pengertian pendidikan: Fungsi, Jenis, Tujuan Pendidikan (Ahli \& Umum).

https://salamadian.com/pengertianpendidikan/. 22 Desember 2020 (00:40) 
[5] Tyas Hanina.2020. 7 Hadits tentang Menuntut IImu bagi Muslim, Harus Diikuti Rendah Hati!. https://www.idntimes.com/life/education/tya s-hanina-1/hadis-tentang-menuntut-ilmu/7. 22 Desember 2020 (00:44)

[6] Abdullah. 2015. Pemrograman Web Untuk Pemula. Cetakan Kedua. PT. Elex Media Komputindo. Jakarta.

[7] Ardhana. 2012. PHP Menyelesaikan Website 30 Juta!. Jasakom. Jakarta

[8] Daqiqil, I. 2011. Framework Codeigniter Sebuah Panduan dan Best Practice. Kumpulan Tutorial Komputer.

[9] Faridl.M. 2015. Fitur Dahsyat Sublime Text. Lug Stikom. Cetakan Pertama.

[10] Haqi, B. 2017. Membuat Aplikasi Antrian Dengan Java Netbeans IDE 8.0.2. Database MySQL. PT. Gramedia.

[11]Josi, A. 2016. Implementasi Framework Bootstrap Pada Website STMIK Prabumulih. Jurnal Mantik Penusa. 1(2). h.4.
[12] Madcoms. A.Offset (Ed.). 2016. Pemrograman PHP dan MySQL Untuk Pemula. Cetakan Kelima. C.V. Andi Offset. Yogyakarta.

[13] Nugroho. Turi (Ed.). 2019. Aplikasi Pemrograman Web Dinamis dengan PHP dan MySQL. Cetakan Kelima. Gava Media. Yogyakarta.

[14]Priyadi. A.Offset (Ed.). 2014. Kolaborasi $S Q L$ dan ERD dalam Implementasi Database. Cetakan Kedua. C.V. Andi Offset. Yogyakarta.

[15] Setiawan, D. 2017. Buku Sakti Pemrograman Web Untuk Pemula. PT. Elex Media Komputindo. Jakarta.

[16] Subhan. Pengembangan Media Pembelajaran Interaktif Pada Mata Pelajaran Komputer dan Jaringan. Jurnal Vocational Teknik Elektronika dan Informatika. 1(7) . h.8. 